\title{
PENGARUH KEPUASAN KERJA, STRES KERJA, DAN KOMITMEN ORGANISASIONAL TERHADAP TURNOVER INTENTION
}

\author{
Dina Sabta Ratnaningsih \\ Universitas Negeri Surabaya \\ dinasabta@gmail.com
}

Abstract

\begin{abstract}
This study aims to find the results of analyzing the phenomena encountered in Elresas Hotel employees regarding job satisfaction, job stress, and organizational commitment as independent variables on turnover intention as the dependent variable on Elresas Hotel employees. The research is quantitative, with variables measured using a Likert scale. Data collection use questionnaires and direct observation. This study uses the entire population of Hotel Elresas Lamongan, amounting to 40 people, as a sample. The data obtained were processed using SPSS VS 18 software in descriptive analysis, classical assumption test and data analysis using multiple linear regression analysis. To test the significance level, simultaneous F-test and t-test were carried out. The research conducted concluded that job satisfaction had a partially insignificant effect on turnover intention, job stress had a positive and significant effect on turnover intention, and organizational commitment partially had an insignificant effect on turnover intention. Simultaneously both the variables of job satisfaction, job stress and organizational commitment influence turnover intention. This study is intended to find out the factors that cause turnover intention at Hotel Elresas Lamongan and can also be used as a suggestion so that employees do not have thoughts of leaving their jobs.
\end{abstract}

Keywords: job satisfaction; organizational commitment; turnover intention; work stress.

\section{PENDAHULUAN}

Keberhasilan suatu organisasi dalam mencapai tujuan tidak lepas dari faktor utamanya yaitu peran Sumber Daya Manusia (SDM). Pada masa ini, Perusahaan sangat membutuhkan SDM yang dapat beradaptasi, tangkas, sangat berkomitmen pada organisasi, cekatan, tertib dengan aturan, dan mampu berkinerja secara efektif (Pranata et al., 2019). Pengelolaan SDM yang baik dapat memberikan keuntungan bagi perusahaan (Santosa, 2016). Oleh karenanya, SDM perlu untuk diberikan pelatihan dan dikembangkan kemampuan yang dimilikinya agar kontribusi yang diberikan pada perusahaan dapat semaksimal mungkin, gagalnya perusahaan dalam menangani dan mengatur SDM di dalamnya dapat memungkinkan terbentuknya harapan karyawan untuk berganti dari jabatan dan tanggungjawab yang diembannya saat ini. Secara umum pada saat seseorang telah membuat pengajuan untuk mundur dari pekerjaan yang dimilikinya sekarang, orang tersebut memiliki tujuan untuk mendapatkan jabatan atau perusahaan yang ingin dimasukinya (Luz et al., 2018).

Hasrat karyawan untuk berhenti dari pekerjaanya dapat didorong oleh banyak sebab. Menurut Farida \& Melinda (2019) satu dari faktor yang memengaruhi turnover intention yaitu komitmen organisasi. Kharismawati \& Dewi (2016) mengemukakan bahwa komitmen yang tinggi dapat menurunkan tingkat turnover. Pengaruh negatif dan signifikan secara parsial ditemukan dari komitmen organisasi terhadap turnover intention (Paat et al., 2017).

Kepuasan kerja juga menjadi satu di antara sebab lain yang berpengaruh kepada turnover intention (Sentana \& Surya, 2017). Menurut Almazrouei et al. (2018) kepuasan kerja disebut sebagai konsepsi yang dijadikan sebagai acuan dasar yang berfungsi menjelaskan sudut pandang turnover oleh karyawan, kebijakan, performa, dan hal lain dalam organisasi. Kepuasan kerja karyawan dapat terbentuk dengan pemberian hak yang sesuai diantaranya, upah yang layak, adanya penghargaan terhadap karyawan berprestasi, serta peluang promosi pada pekerjaannya (Singh \& Singh, 2019). Fitriantini et al. (2019) menyatakan bahwa tingginya kepuasan karyawan akan pekerjaannya sejalan dengan rendahnya turnover, dan begitupun kebalikannya. Perhatian terhadap kepuasan pekerja menjadi suatu hal yang perlu dipelihara agar organisasi memiliki karyawan yang berkinerja dengan baik (Suryanatha \& Ardana, 2014). 
Dina Sabta Ratnaningsih, Pengaruh Kepuasan Kerja, Stres Kerja, dan Komitmen Organisasional terhadap Turnover Intention.

Faktor berikutnya ialah stres kerja, menurut Sopiah \& Sangadji (2020), stres kerja adalah timbulnya ketidakseimbangan fisik dan psikologis akibat ketegangan yang dirasakan berdampak pada perasaan, alur berpikir, dan keadaan orang tersebut. Stres kerja dapat menjadi faktor dari kinerja yang buruk dan juga turnover intention karyawan. (Sutardi et al., 2020). Jika pelaku organisasi tidak dapat menangani stres kerja dengan baik, hal tersebut dapat menyebabkan seseorang bereaksi negatif terhadap lingkungannya (Novitasari, 2020). Stres kerja merupakan penyebab utama terjadinya turnover intention, dengan hasil pernyataan tersebut, meskipun dilakukan peningkatan dari segi pemimpin dan keinginan karyawan untuk loyal pada organisasi belum tentu menurunkan turnover intention jika terjadi stres (Novitasari, 2020). Dengan adanya fakta tersebut, organisasi harus memperhatikan tingkat stres pekerja dan mengontrol tingat stres karyawan tersebut agar tidak menyebabkan karyawan berpikir meninggalkan organisasi. Hal tersebut didukung Sutardi et al. (2020) yang menyatakan stres kerja berpengaruh positif terhadap turnover intention karyawan.

Objek penelitian ini adalah Hotel Elresas. Hotel tersebut berlokasi di pusat kota Lamongan. Hasil wawancara dengan supervisor hotel Elresas, Adrian, menunjukkan bahwa banyak karyawan yang keluar dari pekerjaannya, karyawan juga kurang disiplin untuk datang bekerja tepat waktu, serta terkadang melanggar aturan yang telah ditetapkan manajemen. Berdasarkan pada uraian latar belakang masalah tersebut, tujuan penelitian ini untuk mengetahui pengaruh komitmen organisasional, kepuasan kerja dan stres kerja terhadap turnover intention pada karyawan Hotel Elresas Lamongan.

\section{KAJIAN PUSTAKA DAN PENGEMBANGAN HIPOTESIS}

\section{Kepuasan Kerja}

Menurut Setiawan (2017) kepuasan kerja merupakan sesuatu yang dapat membuat seorang individu merasa senang dengan pekerjaan yang dilakukan. Menurut Luthans (2015) kepuasan kerja diartikan sugesti positif yang terbentuk setelah karyawan melakukan penilaian terhadap pekerjannya berdasarkan nilai imbalan yang diperoleh. Mangkunegara (2019) menyatakan kepuasan kerja memiliki dua pokok yang memengaruhinya yaitu, (1) Faktor karyawan terdiri dari kecerdasan IQ, kecakapan khusus, umur, jenis kelamin, kondisi fisik, pendidikan, pengalaman kerja, masa kerja, kepribadian, emosi, cara berfikir, pendidikan, pengalaman kerja, masa kerja, perpepsi, dan sikap kerja. (2) Faktor pekerjaan diantaranya, jenis pekerjaan, struktur organisasi, pangkat (golongan), kedudukan, mutu pengawasan, jaminan finansial, kesempatan, promosi jabatan, interaksi sosial, dan hubungan kerja. Robbins \& Judge (2015) menyatakan kepuasan kerja akan banyak berdampak pada performa kerja karyawan, organizational citizenship behavior $(\mathrm{OCB})$ karyawan, perilaku mengindar dan pindah kerja, dan kepuasan hidup karyawan. Issa et al. (2013) mengemukakan indikator kepuasan kerja terdiri dari, (1) pekerjaan itu sendiri, (2) gaji, (3) kesempatan promosi, (4) pengawasan, (5) rekan kerja.

\section{Stres Kerja}

Menurut Asih et al. (2018) stres merupakan suatu keadaan akibat ketidakseimbangan dari tuntutan yang harus dipenuhi dengan kemampuan, keahlian, dan cara berpikir seseorang, jika ketimpangan yang terbentuk dalam tingkatan tinggi akan semakin tinggi juga stres yang dialami individu tersebut. Perasaan terdesak dengan tekanan yang ada ketika pekerja sedang melakukan pekerjannya disebut stres kerja (Mangkunegara, 2019). Kalimat tersebut dapat dihubungkan dengan pernyataan Luthans (2015) stres kerja adalah perubahan perilaku, sikap, dan hal lain yang berkaitan dengan sifat sesorang dengan keadaan terpaksa mendorongnya untuk bertindak tidak wajar dari tugas yang biasa dilakukan. Stres termasuk hal umum sering terjadi dalam lingkungan pekerjaan yang biasanya dirasakan sebagai ketidakpuasan kerja dan diwujudkan dengan adanya kemarahan, frustasi, permusuhan dan kejengkelan. Selain itu, respon pasif dari stres diwujudkan dengan perasaan jenuh, muak, dan putus asa (Kaswan, 2015). Robbins \& Judge (2015:434) merincikan gejala dari stres kerja meliputi: (1) Gejala fisiologis, (2) Gejala psikologis, (3) Gejala perilaku. Stres dapat muncul karena adanya interaksi yang terbentuk antara sesorang dengan orang lain, keadaan ataupun lingkungan sekelilingnya. Selain itu, stres dalam bekerja juga terbentuk jika ada tanggapan dari orang yang terkait dan diwujudkan berupa sikap serta keadaan fisik yang akhirnya memberikan desakan yang belum 
tentu mampu dipenuhi orang tersebut ketika bekerja (Wijono, 2015: 168). Menurut Paat et al. (2017) stres kerja menjadi salah satu faktor yang menyebabkan turnover intention pada karyawan. Indikator stres kerja terdiri dari tiga aspek yaitu, stressor organisasi, stressor individual, dan ketaatan peraturan dari karyawan (Manurung \& Ratnawati, 2012).

\section{Komitmen Organisasi}

Menurut Gumilar et al. (2020) komitmen organisasional dikatakan sebagai alat ukur keterikatan karyawan dengan organisasi apakah karyawan mau untuk bergerak sejalan serta memberikan yang terbaik dalam kinerjanya demi tujuan organisasi. Komitmen yang tinggi harus didukung dengan adanya pemenuhan hak -hak karyawan yang sesuai (Edison et al., 2017). Pendapat ini dilanjutkan oleh Eliyana et al. (2019) yang menyatakan komitmen organisasi adalah pernyataan bahwa karyawan peduli terhadap kesuksesan dan perkembangan organisasi dengan diiringi perilaku yang mencerminkan loyalitas pada organisasi tersebut. Komitmen organisasi juga dapat diartikan sebagai perasaan puas karyawan terhadap pekerjaannya, sehingga menimbulkan rasa ketergantungan, tanggung jawab dan komitmen pada organisasi. Sopiah \& Sangadji (2020) menyebutkan beberapa aspek yang diduga memengaruhi tekad dan komitmen seseorang terhadap organisasi sebagai berikut: (1) Faktor diri pribadi (2) Karakter dari pekerjaan tersebut. Dijelaskan Robbins \& Judge (2015) komitmen organisasi memiliki tiga indikator yaitu: (1) Komitmen afektif: adanya ikatan seorang pekerja dengan perusahaan yang sulit dilepaskan, (2) Komitmen berkelanjutan: kecukupan dari segi finansial pekerja terpenuhi bila tetap bersama perusahaannya sekarang, (3) Komitmen normatif: adanya latar belakang yang tidak bisa dijelaskan yang membuat karyawan bersikeras melanjutkan pekerjaan di perusahaannya tempat bekerja saat itu.

\section{Turnover Intention}

Sesuatu yang sedang dipikirkan sehingga mendorong seseorang untuk melakukannya disebut intention, untuk turnover sendiri memiliki arti usainya hubungan kerja antara karyawan dengan perusahaannya atas kehendak sendiri. Sehingga, turnover intention merupakan keinginan yang telah direnungkan dan dipikirkan dengan matang atas kehendaknya sendiri untuk memutuskan ikatan dengan pekerjaannya saat itu (Tampubolon \& Sagala, 2020). Menurut Hartono dalam Dharma (2013) sinyal yang menandakan adanya indikasi karyawan keluar dari pekerjaannya adalah: (1) Semakin buruknya tingkat absensi, (2) Tidak cekatan dalam bekerja, (3) Peningkatan pelanggaran tata tertib kerja, (3) Peningkatan protes terhadap atasan, (4) Perilaku yang tidak biasa dilakukan. Robbins and Judge (2015) menjelaskan bahwa sesorang yang keluar dari pekerjaannya atas pikirannya sendiri dapat terjadi sebagai tindakan sukarela (voluntary turnover) ataupun tidak sukarela (involuntary turnover). Voluntary turnover dapat terjadi jika seseorang telah memiliki rencana cadangan ketika memutuskan untuk keluar. Keterbalikan dari hal tersebut, involuntary turnover berkaitan langsung pada kewenangan atasan terhadap kelanjutan pekerja tersebut.

\section{Hubungan antar Variabel}

Studi yang dilakukan oleh Apriantini et al. (2021) ditemukan keterhubungan negatif dan signifikan antara kepuasan kerja karyawan dengan turnover karyawan. Li et al. (2019) meneliti perawat di Beijing menemukan bahwa niat pegawai untuk keluar akan menurun jika telah merasa puas terhadap pekerjaan yang dimilikinya. Zhang et al. (2018) di China meneliti keterikatan turnover intention dengan kepuasan kerja yang menunjukkan ikatan keterbalikan, jika satu variabel meningkat maka variabel lain akan menurun. Sedangkan O'Connor (2018) di Texas menemukan hubungan berlawanan antara kepuasan karyawan saat bekerja dengan turnover intention. Hasil studi lain menemukan arah negatif antara kepuasan kerja dengan turnover intention (Liu et al., 2018; dan Amri et al., 2017).

H1: Kepuasan kerja memiliki pengaruh negatif dan signifikan terhadap turnover intention pada karyawan Hotel Elresas Lamongan.

Hubungan maupun pengaruh secara langsung dan tidak langsung antara stres kerja dan turnover intention telah banyak diteliti (Monica \& Putra, 2017). Lim \& Cho (2018) menemukan bahwa stres kerja secara langsung berpengaruh positif serta signifikan terhadap turnover intention. Studi dari 
Dina Sabta Ratnaningsih, Pengaruh Kepuasan Kerja, Stres Kerja, dan Komitmen Organisasional terhadap Turnover Intention.

Soelton \& Atnani (2018) terdapat keterlibatan stres kerja terhadap dorongan turnover intention. Selanjutnya, penelitian yang dilakukan kepada 100 karyawan bank mandiri menegaskan antara stres kerja dan turnover intention saling berkaitan. Studi oleh Haholongan (2018), Labrague et al. (2018), dan Bawawa et al. (2021), menemukan hubungan positif dan signifikan antara stres kerja dengan turnover intention.

$\mathrm{H} 2$ : Stres kerja memiliki pengaruh positif dan signifikan terhadap turnover intention pada karyawan Hotel Elresas Lamongan.

Kerdngern \& Thanitbenjasith (2017) memerlihatkan komitmen organisasional langsung berdampak negatif dan signifikan sebagai salah satu penyebab terjadinya turnover intention. Prabowo (2018) menguatkan pendapat tersebut, bahwa ada hubungan negatif antara komitmen organisasi dengan niatan karyawan untuk berpindah. Studi yang dilakukan oleh Lestari \& Prahlawan (2016), Ramalho Luz et al. (2018), Chan \& Ao (2019), dan Agarwal \& Sajid (2017) menguatkan temuan adanya hubungan negatif dan signifikan antara komitmen organisasi dengan turnover intention.

H3: Komitmen organisasi memiliki pengaruh negatif dan signifikan terhadap turnover intention pada karyawan Hotel Elresas Lamongan.

Kepuasan kerja, stres kerja, dan komitmen organisasi secara simultan berpengaruh terhadap turnover intention (Poeh \& Soehari, 2017). Pendapat tersebut didukung oleh hasil penelitian dari Budiyono (2016), Khakim et al. (2017), dan Apriantini et al. (2021) yang menemukan adanya pengaruh dari variabel kepuasan kerja, stres kerja, dam komitmen organisasi terhadap turnover intention.

H4: Kepuasan kerja, stres kerja, dan komitmen organisasi secara simultan berpengaruh terhadap turnover intention pada karyawan Hotel Elresas Lamongan.

Gambar 1 adalah kerangka pemikiran penelitian ini.

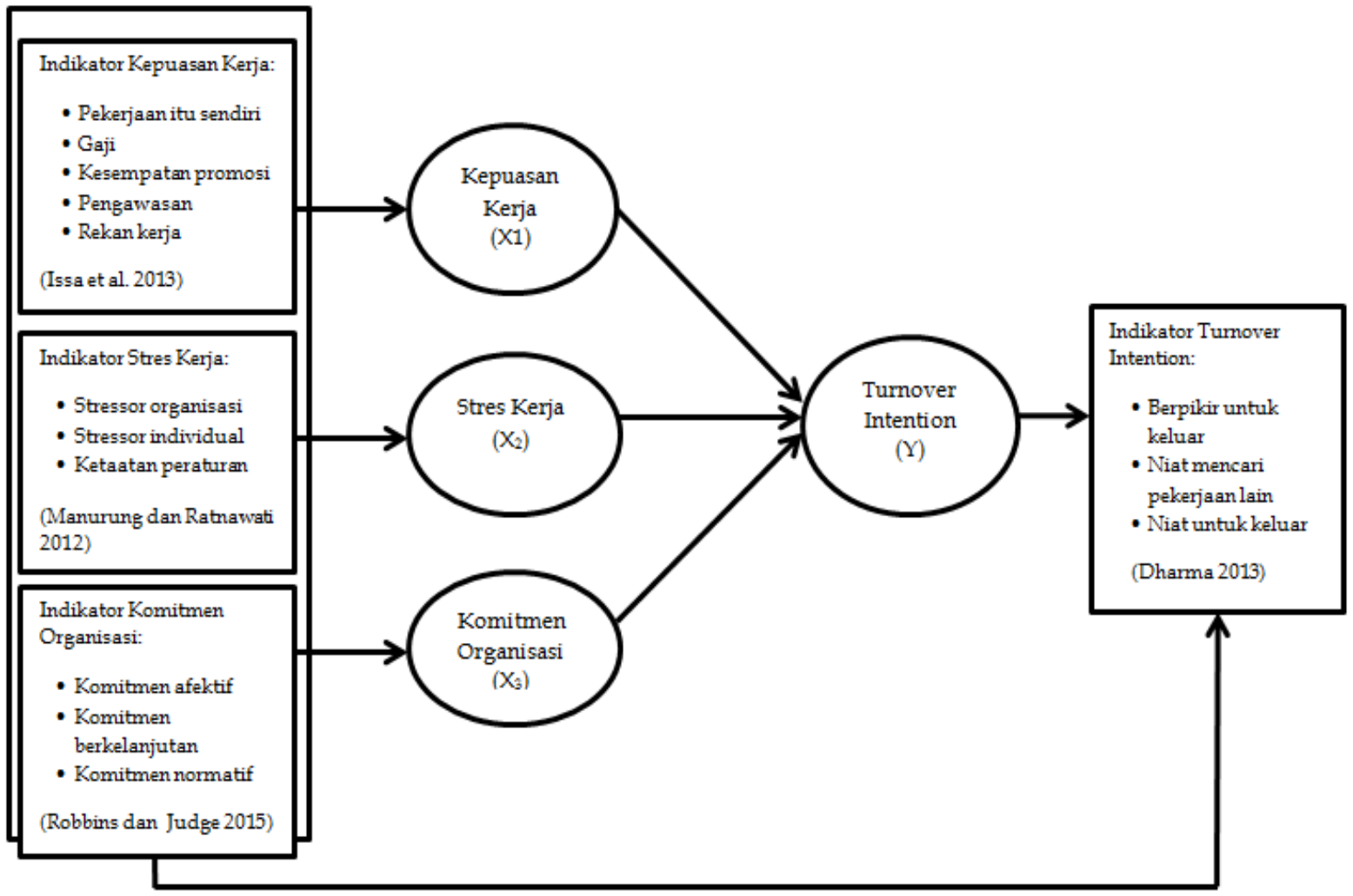

Gambar 1. KERANGKA PEMIKIRAN 


\section{METODE PENELITIAN}

Jenis penelitian ini adalah penelitian kuantitatif. Data yang digunakan berupa data pimer yang diperoleh secara langsung dari narasumber yang digunakan sebagai sampel penelitian dengan metode kuesioner, wawancara, serta observasi dan data sekunder yang diperoleh dari catatan serta dokumen perusahaan sebagai pendukung dari data primer.

Populasi penelitian adalah karyawan Hotel Elresas berjumlah 40 orang. Teknik sampling yang digunakan adalah total sampling di mana jumlah sampel sama dengan jumlah populasi. Teknik tersebut sesuai dengan penjelasan Sugiyono (2016) yang mengungkapkan bahwa total sampling dapat dilakukan jika populasi yang ada relatif kecil atau disebut sensus ketika seluruh populasi menjadi sampel penelitian. Variabel yang digunakan pada studi ini terdiri dari dua jenis yaitu variabel independen dan variabel dependen. Kepuasan kerja, stres kerja dan komitmen organisasi berfungsi sebagai variabel independen sementara turnover intention sebagai variabel dependen.Teknik analisis data menggunakan analisis regresi linear berganda. Uji pengaruh yang dilakukan antara lain,uji asumsi klasik, uji t dan uji $\mathrm{F}$, seluruh data diolah dengan menggunakan SPSS 18. Skala pengukuran dalam kuesioner yang dijadikan sumber data menggunakan skala Likert dimulai dari 1 (sangat tidak setuju) hingga 5 (sangat setuju).

\section{HASIL DAN PEMBAHASAN}

\section{Hasil Uji Validitas dan Reliabilitas}

Nilai dari uji validitas yang telah dilakukan pada masing-masing variabel baik dari kepuasan kerja, stres kerja, komitmen organisasional, dan turnover intention bernilai lebih besar daripada $r$ tabel $(0,3120)$ sehingga kuesioner penelitian telah teruji valid. Hasil tersebut sesuai dengan kriteria penilaian uji validitas menurut Ghozali (2018) yang mana jika hasil $\mathrm{r}_{\text {hitung }}>\mathrm{r}_{\text {tabel }}$ maka data tersebut dinyatakan valid. Hasil uji reliablilitas nilai alpha dari variabel kepuasan kerja $(0,903)$, stres kerja $(0,762)$, komitmen organisasi $(0,781)$, dan turnover intention $(0,819)$ yang semuanya bernilai lebih besar dari 0,60. Berdasarkan kaidah yang berlaku menurut (Ghozali, 2018) jika nilai Cronbach Alpha lebih besar dari 0,6 maka data dalam uji reliabilitas dapat dinyatakan reliable.

\section{Hasil Uji Analisis Deskriptif}

Jawaban dari responden terkait dengan pernyataan tentang kepuasan kerja, stres kerja, dan komitmen organisasi menghasilkan nilai mean sebagai berikut: variabel kepuasan kerja $(3,13)$ dengan kategori sedang, variabel stres kerja $(3,42)$ dengan kategori tinggi, variabel komitmen organisasi $(3,36)$ dengan kategori sedang. Hasil tersebut diukur sesuai dengan kaidah yang dikemukakan oleh (Sugiyono, 2016)

\section{Hasil Uji Normalitas}

Uji normalitas, jika nilai signifikansi > 0,05 maka data berdistribusi normal (Ghozali, 2018) Berdasarkan uji normalitas kolmogrov-sminov nilai signifikansi kolmogrov-smirnov sebesar 0,698 > 0,05 . Jadi data berdistribusi normal.

\section{Hasil Uji Multikolinearitas}

Menurut Ghozali (2018) model regresi dinyatakan bebas dari multikolinearitas jika nilai VIF < 10 dan nilai tolerane $>0,1$. Semua nilai yang berkaitan dengan uji multikolinearitas bernilai di atas 0,10 untuk hasil tolerancenya, dan semua hasil tidak ada yang melebihi 10 untuk nilai Variance Inflaction Factor (VIF). Dengan kata lain, tidak ditemui adanya gejala multikolinearitas dan pengujian selanjutnya dapat dilanjutkan.

\section{Hasil Uji Heteroskedastisitas}

Data tidak terjadi heteroskedastisitas apabila nilai signifikansi melebihi 0,05 (Ghozali, 2018). Dari hasil pengujian pada tabel 1 , semua variabel memiliki nilai signifikansi lebih besar dari 0,05 , sehingga tidak terjadi heteroskedastisitas dalam penelitian ini. 
Dina Sabta Ratnaningsih, Pengaruh Kepuasan Kerja, Stres Kerja, dan Komitmen Organisasional terhadap Turnover Intention.

Tabel 1.

HASIL UJI HETEROSKEDASTISITAS

\begin{tabular}{cccc}
\hline & Model & t & Sig. \\
\hline & (Constant) & .576 & .568 \\
1 & Kepuasan Kerja & -.968 & .339 \\
& Stres Kerja & .087 & .931 \\
& Komitmen Organisasi & 1.417 & .165 \\
\hline
\end{tabular}

a. Dependent Variable: Abs_RES

Sumber: output SPSS, 2021

Hasil Uji Analisis Regresi Linear Berganda

Tabel 2.

HASIL ANALISIS REGRESI LINEAR BERGANDA

\begin{tabular}{ccccccc}
\hline \multirow{2}{*}{ Model } & \multicolumn{2}{c}{$\begin{array}{c}\text { Unstandardized } \\
\text { Coefficients }\end{array}$} & $\begin{array}{c}\text { Standardized } \\
\text { Coefficients }\end{array}$ & \\
\cline { 3 - 5 } & & B & Std. & & & \\
& & Error & Beta & t & Sig. \\
\hline 1 & (Constant) & 30.655 & 6.072 & & 5.048 & .000 \\
& Kepuasan Kerja & -.146 & .080 & -.276 & -1.833 & .075 \\
& Stres Kerja & .419 & .136 & .467 & 3.078 & .004 \\
& Komitmen Organisasi & -.289 & .146 & -.277 & -1.974 & .056 \\
\hline
\end{tabular}

a. Dependent Variable: TURNOVER INTENTION

Sumber: Data primer diolah, 2021

Dari tabel 2, diperoleh persamaan regresi (1).

$\mathrm{Y}=30,665-0,149 \mathrm{X}_{2}+\mathrm{e}$.

Nilai kepuasan kerja di Hotel Elresas Lamongan sebesar -0,146. Jika terjadi penurunan sebesar 1 satuan pada komitmen organisasi akan berdampak pada naiknya turnover intention sebanyak 0,146 dan menandakan adanya hubungan yang negatif. Stres kerja di Hotel Elresas Lamongan memiliki nilai beta $=0,419$. Apabila stres kerja meningkat juga akan diikuti dengan peningkatan turnover intention sebesar 0,419. Hasil pengujian komitmen organisasi diperoleh nilai beta sebesar -0,289. Dengan demikian terdapat hubungan negatif atau berlawanan arah. Bertambahnya komitmen yang dirasakan karyawan sebanyak satu satuan akan menurunkan turnover intention senilai 0,289 satuan.

\section{Hasil Uji t}

Berdasarkan tabel 2, kepuasan kerja (X1) memiliki $t_{\text {hitung }}$ senilai $-1,922$ dan $t_{\text {tabel }}=1,68830$. diketahui $t_{\text {hitung }}>t_{\text {tabel }}$ dengan nilai signifikansi 0,075 $>0,05$ (tidak signifikan). Hal ini berarti variabel kepuasan kerja tidak berpengaruh terhadap variabel turnover intention. Stres kerja (X2) memiliki hasil $t_{\text {hitung }}$ yakni 3,078 lebih besar daripada $t_{\text {tabel }}=1,6830$ dan nilai signifikansi $0,04<0,05$. Jadi, variabel stres kerja berpengaruh positif dan signifikan terhadap variabel turnover intention. Komitmen organisasi (X3) memiliki $t_{\text {hitung }}$ senilai $-1,974$ lebih besar jika dibandingkan $t_{\text {tabel }}=1,6830$ dan signifikansi $0,056>0,05$. Artinya komitmen organisasi tidak berpengaruh terhadap turnover intention karyawan.

\section{Hasil Uji F}

Dasar pengambilan keputusan uji $\mathrm{F}$ apabila nilai signifikansi $<0,05$ maka variabel independen berpengaruh terhadap variabel dependen (Ghozali, 2018). Nilai signifikansi pada tabel 3, sebesar 0,04 $<0,05$. Hal ini berarti secara bersama-sama, kepuasan kerja, stres kerja, dan komitmen organisasi berpengaruh terhadap turnover intention pada karyawan Hotel Elresas Lamongan. 
Tabel 3.

HASIL UJI F

\begin{tabular}{ccccccc}
\hline & Model & Sum of Squares & df & Mean Square & $\boldsymbol{F}$ & Sig. \\
\hline 1 & Regression & 279.927 & 3 & 93.309 & 5.196 & $.004^{\mathrm{a}}$ \\
Residual & 646.473 & 36 & 17.958 & & \\
Total & 926.400 & 39 & & & \\
a. Predictors: (Constant), Komitmen Organisasi, Kepuasan Kerja, Stres Kerja \\
b. Dependent Variable: Turnover Intention \\
\hline
\end{tabular}

Sumber: Output SPSS, 2021

\section{Pengaruh Kepuasan Kerja terhadap Turnover Intention}

Pengujian yang dilakukan menunjukkan kepuasan kerja tidak berpengaruh terhadap turnover intention pada karyawan Hotel Elresas Lamongan. Berdasarkan hasil kuesioner yang diperoleh, karyawan Hotel Elresas Lamongan memiliki tingkat kepuasan kerja yang cukup. Berdasarkan wawancara yang dilakukan, karyawan sebenarnya menginginkan gaji yang lebih tinggi dari yang diterimanya sekarang, namun gaji yang diterima saat ini sudah dirasa cukup untuk memenuhi kebutuhan sehari-hari. Sehingga, keinginan karyawan untuk mendapat kenaikan gaji tidak terlalu kuat.Wawancara yang dilakukan pada karyawan menggambarkan tingkat kepuasan yang dirasakan oleh karyawan tergantung pada kebutuhan dari masing-masing individu. Pernyataan ini mendukung teori yang dikemukakan Luthans (2015) kepuasan kerja diartikan sugesti positif yang terbentuk setelah karyawan melakukan penilaian terhadap pekerjaannya berdasarkan nilai imbalan yang diperoleh. Hasil dari studi ini yang menunjukkan kepuasan kerja tidak berpengaruh terhadap turnover intention sejalan dengan (Astamarini, 2019), (Karomah, 2020), dan (Zhang et al., 2018). Namun bertentangan dengan Destiyana \& Sarnianto (2019), Melky (2015), dan Prasetio et al. (2018) yang menemukan bahwa kepuasan kerja tidak berpengaruh terhadap turnover intention.

\section{Pengaruh Stres Kerja terhadap Turnover Intention}

Pada penelitian ini ditemukan bahwa stres kerja memiliki pengaruh positif dan signifikan terhadap turnover intention pada karyawan Hotel Elresas Lamongan. Nilai yang ditunjukkan adalah positif y artinya apabila di Hotel Elresas Lamongan stres yang dirasakan karyawan naik, pikiran untuk keluar dari pekerjaannya juga akan semakin tinggi. Mengacu pada hasil analisis deskriptif, tanggapan karyawan terhadap pernyataan stres kerja pada kuesioner tergolong tinggi yang artinya stres kerja sangat dirasakan oleh karyawan Hotel Elresas Lamongan. Dari hasil observasi, ditemukan kebanyakan karyawan megeluh atas pekerjaannya karena beban kerja yang tinggi dan waktu istirahat yang singkat sehingga membuat beberapa dari karyawan merasa stres. Hasil uji ini sejalan dengan studi dari Nafisah et al. (2020), Soelton \& Atnani (2018), dan Bawawa et al. (2021) di mana stres kerja berpengaruh positif dan signifikan terhadap turnover intention. Pendapat yang berbeda dikemukakan oleh Ramlawati et al. (2021),dan Kurniawati et al. (2018) yang menyebutkan bahwa stres kerja tidak memiliki pengaruh terhadap turnover intention.

\section{Pengaruh Komitmen Organisasi terhadap Turnover Intention}

Pengujian komitmen organisasi menemukan hasil komitmen organisasi tidak berpengaruh terhadap turnover intention karyawan Hotel Elresas Lamongan. Seperti dijabarkan sebelumnya, dari proses observasi yang dilakukan ditemui beberapa karyawan yang melanggar aturan manajemen dan terlambat untuk datang tepat waktu, yang mengindikasikan karyawan kurang memiliki komitmen kuat pada organisasi sehingga menimbulkan keinginan untuk keluar dari pekerjaannya. Hasil penelitian ini mendukung penelitian Lu et al. (2017), Hidayati \& Trisnawati (2016), dan Soelton \& Atnani (2018) bahwa komitmen organisasi memiliki pengaruh negatif tidak signifikan terhadap turnover intention karyawan. Pendapat yang berbeda ditemukan oleh Setiawan \& Harahap (2016) dan Sentana \& Surya (2017) di mana komitmen organisasi berpengaruh positif dan signifikan terhadap turnover intention. 
Dina Sabta Ratnaningsih, Pengaruh Kepuasan Kerja, Stres Kerja, dan Komitmen Organisasional terhadap Turnover Intention.

Pengaruh Kepuasan Kerja, Stres Kerja, dan Komitmen Organisasi terhadap Turnover Intention Pengujian kepuasan kerja, stres kerja dan komitmen organisasi secara simultan menemukan hasil bahwa baik kepuasan kerja, stres kerja, dan komitmen organisasi berpengaruh terhadap turnover intention pada karyawan Hotel Elresas Lamongan. Artinya ketiga variabel tersebut memengaruhi tingkat turnover intention pada karyawan Hotel Elresas Lamongan. Hasil tersebut mendukung penelitian Paat et al. (2017), Bawawa et al. (2021), dan Amri et al. (2017) bahwa kepuasan kerja, stres kerja, dan komitmen organisasi berpengaruh terhadap turnover intention karyawan.

\section{KESIMPULAN}

Berdasarkan hasil pengujian, dapat disimpulkan bahwa kepuasan kerja tidak berpengaruh terhadap turnover intention pada karyawan Hotel Elresas Lamongan. Stres kerja memiliki pengaruh positif dan signifikan terhadap turnover intention pada karyawan Hotel Elresas Lamongan, dengan demikian apabila stres kerja meningkat akan ikut meningkatkan turnover intention. Komitmen organisasi tidak berpengaruh terhadap turnover intention pada karyawan Hotel Elresas Lamongan. Secara simultan kepuasan kerja, stres kerja dan komitmen organisasi berpengaruh terhadap turnover intention pada karyawan Hotel Elresas Lamongan.

Sejalan dengan kesimpulan yang telah dibuat, manajemen Hotel Elresas Lamongan diharapkan dapat mengurangi tingkat stres karyawan dengan memberikan beban kerja yang sesuai bagi setiap karyawan, sehingga tidak menimbulkan stress kerja pada karyawan yang berpeluang pada peningkatan turnover intention karyawan. Hasil penelitian ini tidak menemukan pengaruh signifikan antara kepuasan kerja dan komitmen organisasi terhadap turnover intention, sehingga diharapkan pada penelitian selanjutnya dapat menggunakan variabel lain sebagai faktor yang memengaruhi turnover secara signifikan.

\section{DAFTAR PUSTAKA}

Agarwal, P., \& Sajid, S. (2017). A Study of Job Satisfaction, Organizational Commitment and Turnover Intention among Public and Private Sector Employees. Journal of Management Research, 17(3), 123-136.

Almazrouei, H. S., Zacca, R., Evans, J. M., \& Dayan, M. (2018). Great Expectations: The Moderating Role of Pre-Departure Opinion on the Relationship between Organizational Justice and Expatriates' Commitment and Job Satisfaction. Journal of Global Mobility, 6(2), 178-193. https://doi.org/10.1108/JGM-07-2017-0031

Amri, U., M, A., \& Riyanto, S. (2017). Pengaruh Kepuasan Kerja, Stres Kerja, dan Komitmen Organisasi terhadap Turnover Intention pada Head Office PT. Thamrin Brothers Palembang. Jurnal Kompetitif, $6(1), \quad 109-128$. https://doi.org/http://dx.doi.org/10.52333\%2Fkompetitif.v6i1.437

Apriantini, S. A. M., Imbayani, I. G. A., \& Ribek, P. K. (2021). Pengaruh Job Stress, Kepuasan Kerja, dan Komitmen Organisasi terhadap Turnover Intention Karyawan Hotel Kamandalu Ubud. Jurnal Emas, 2(2), 71-81.

Asih, G. Y., Widhiastuti, H., \& Dewi, R. (2018). Stress Kerja (1st ed.). Semarang: Semarang University Press.

Astamarini, R. O. (2019). Analisis Pengaruh Job Embeddedness dan Kepuasan Kerja terhadap Turnover Intention pada Pt Purnama Indonesia. Jurnal Ilmu Manajemen (JIM), 7(2), 430-436. https://jurnalmahasiswa.unesa.ac.id/index.php/jim/article/view/26370

Bawawa, A. A., Lengkong, V. P. K., \& Taroreh, R. N. (2021). Pengaruh Kepuasan Kerja, Komitmen Organisasional dan Stres Kerja pada Pt. SIG Asia Kota Bitung. Jurnal Emba, 9(2), 785-795. 
https://doi.org/https://doi.org/10.35794/emba.v9i2.33750

Budiyono, R. (2016). Analisa Pengaruh Kepuasan Kerja, Stress Kerja, dan Komitmen Organisasi terhadap Turnover Intention (Studi Pada PT. Duta Service Semarang). Jurnal STIE Semarang, $8(1), 37-53$.

Chan, S. H. J., \& Ao, C. T. D. (2019). The Mediating Effects of Job Satisfaction and Organizational Commitment on Turnover Intention, in the Relationships between Pay Satisfaction and WorkFamily Conflict of Casino Employees. Journal of Quality Assurance in Hospitality and Tourism, 20(2), 206-229. https://doi.org/10.1080/1528008X.2018.1512937

Destiyana, B., \& Sarnianto, P. (2019). Model Hubungan Kepuasan Organisasional dan Stres Kerja terhadap Turnover Intention. Jurnal Riset Manajemen dan Bisnis (JRMB), 4(1), 557-564. http://jrmb.ejournal-feuniat.net/index.php/JRMB/article/view/333

Dharma, C. (2013). Hubungan antara Turnover Intention dengan Komitmen Organisasional Di PT. X. Medan. Jurnal Ekonomi dan Bisnis Jurusan Administrasi Niaga Politeknik Negeri Medan, 1(2), $1-94$.

Edison, E., Anwaw, Y., \& Komariyah, I. (2017). Manajemen Sumber Daya Manusia. Bandung: Alfabeta.

Eliyana, A., Ma'arif, S., \& Muzakki. (2019). Job Satisfaction and Organizational Commitment Effect in the Transformational Leadership towards Employee Performance. European Research on Management and Business Economics, 25(3), 144-150. https://doi.org/10.1016/j.iedeen.2019.05.001

Farida, U., \& Melinda, B. (2019). Peran Beban Kerja dan Komitmen Organisasi terhadap Turnover Pekerja. Jurnal Ilmu Manajemen, 9(1), 52-63.

Fitriantini, R., Agusdin, A., \& Nurmayanti, S. (2019). Pengaruh Beban Kerja, Kepuasan Kerja dan Stres Kerja terhadap Turnover Intention Tenaga Kesehatan Berstatus Kontrak di Rsud Kota Mataram. Distribusi - Journal of Management and Business, 8(1), 28-38. https://doi.org/10.29303/distribusi.v8i1.100

Ghozali, I. (2018). Aplikasi Analisis Multivariate dengan Program IBM SPSS 25 (9th ed.). Semarang: Badan Penerbit Universitas Diponegoro.

Gumilar, G. G., Ratnasari, S. L., \& Zulkifli. (2020). Komitmen Organisasional: Budaya Organisasi, Kepemimpinan Kepala Sekolah, Lingkungan Sekolah, dan Kepuasan Kerja. Journal Dimensi, 9(1), 48-56. https://www.journal.unrika.ac.id/index.php/jurnaldms/article/viewFile/2318/1649

Haholongan, R. (2018). Stres Kerja, Lingkungan Kerja terhadap Turnover Intention Perusahaan. Jurnal Manajemen Indonesia, 18(1), 61-67. https://doi.org/10.25124/jmi.v18i1.1260

Hidayati, N., \& Trisnawati, D. (2016). Pengaruh Kepuasan Kerja dan Stress Kerja terhadap Turnover Intentions Karyawan Bagian Marketing PT. Wahana Sahabat Utama. Eksis, 11(1), 22-37. https://doi.org/https://doi.org/10.26533/eksis.v11i1.27

Issa, D. A. R. M., Ahmad, F., \& Gelaidan, H. M. (2013). Job Satisfaction and Turnover Intention Based on Sales Person Standpoint. Middle East Journal of Scientific Research, 14(4), 525-531. https://doi.org/10.5829/idosi.mejsr.2013.14.4.11172

Karomah. (2020). Pengaruh Kepuasan Kerja dan Job Insecurity terhadap Turnover Intention pada Pegawai Kontrak Sekolah X. Jurnal Ilmu Manajemen, 17, 38-47. 
Dina Sabta Ratnaningsih, Pengaruh Kepuasan Kerja, Stres Kerja, dan Komitmen Organisasional terhadap Turnover Intention.

https://doi.org/https://doi.org/10.21831/jim.v17i1.34774

Kaswan. (2015). Sikap Kerja: Dari Teori dan Implementasi Sampai Bukti. Bandung: Alfabeta.

Kerdngern, N., \& Thanitbenjasith, P. (2017). Influence of Contemporary Leadership on Job Satisfaction, Organizational Commitment, and Turnover Intention: A Case Study of the Construction Industry in Thailand. International Journal of Engineering Business Management, 9, 1-8. https://doi.org/10.1177/1847979017723173

Khakim, M. N., Retnowati, N., \& Haryono. (2017). Pengaruh Kepuasan Kerja, Stres Kerja, dan Komitmen Organisasi terhadap Turnover Intention di Telkomsel Distribution Center Kabupaten Jombang. Jurnal Manajemen Branchmark, 3(3), 348-360.

Kharismawati, D. A. P., \& Dewi, I. G. A. M. (2016). Pengaruh Komitmen Organisasional, Dukungan Sosial, dan Iklim Etika terhadap Turnover Intention. In E-Jurnal Manajemen Unud (Vol. 5, Issue 2, pp. 1368-1398).

Kurniawati, N. I., Werdani, R. E., \& Pinem, R. J. (2018). Analisis Pengaruh Work Family Conflict dan Beban Kerja terhadap Stres Kerja dalam Memengaruhi Turnover Intention (Studi Pada Karyawan PT. Bank Negara Indonesia (Persero), Tbk Wilayah Semarang). Jurnal Administrasi Bisnis, 7(2), 95-102. https://doi.org/10.14710/jab.v7i2.22694

Labrague, L. J., Gloe, D. S., McEnroe-Petitte, D. M., Tsaras, K., \& Colet, P. C. (2018). Factors Influencing Turnover Intention among Registered Nurses in Samar Philippines. Applied Nursing Research, 39, 200-206. https://doi.org/10.1016/j.apnr.2017.11.027

Lestari, D., \& Prahlawan, W. (2016). Pengaruh Work Family Conflict, Komitmen Organisasi terhadap Turnover Intention dengan Kepuasan Kerja Sebagai Variabel Intervening. Jurnal Riset Bisnis Dan Manajemen Tirtayasa, 2(2), 165-183.

Li, N., Zhang, L., Xiao, G., Chen, J., \& Lu, Q. (2019). The Relationship between Workplace Violence, Job Satisfaction and Turnover Intention in Emergency Nurses. International Emergency Nursing, 45(February), 50-55. https://doi.org/10.1016/j.ienj.2019.02.001

Lim, Y.-H., \& Cho, Y.-C. (2018). Effects of Job Stress, Fatigue, Burnout, and Job Satisfaction on Turnover Intention among General Hospital Nurses. Journal of the Korea Academia-Industrial Cooperation Society, 19(6), 264-274. https://doi.org/10.5762/KAIS.2018.19.6.264

Liu, W., Zhao, S., Shi, L., Zhang, Z., Liu, X., Li, L., Duan, X., Li, G., Lou, F., Jia, X., Fan, L., Sun, T., \& Ni, X. (2018). Workplace Violence, Job Satisfaction, Burnout, Perceived Organisational Support and Their Effects on Turnover Intention among Chinese Nurses In Tertiary Hospitals: A Cross-Sectional Study. BMJ Open, 8(6), 1-11. https://doi.org/10.1136/bmjopen-2017019525

Lu, Y., Hu, X. M., Huang, X. L., Zhuang, X. D., Guo, P., Feng, L. F., Hu, W., Chen, L., Zou, H., \& Hao, Y. T. (2017). The Relationship between Job Satisfaction, Work Stress, Work-Family Conflict, and Turnover Intention among Physicians in Guangdong, China: A cross-sectional study. BMJ Open, 7(5), 1-12. https://doi.org/10.1136/bmjopen-2016-014894

Luthans, F. (2015). Perilaku Organisasi (ed.); 10th ed.). Yogyakarta: PT. Andi.

Luz, C. M. D., R., Paula, S. L. D., \& Oliveira, L. M. B. D. (2018). Organizational Commitment, Job Satisfaction and Their Possible Influences on Intent to Turnover. Emerald Publishing Limited, 25(1), 84-101. 
Mangkunegara, A. A. A. P. (2019). Evaluasi Kinerja SDM (8th ed.). Bandung: Refika Aditama.

Manurung, M. T., \& Ratnawati, I. (2012). Analisis Pengaruh Stres Kerja dan Kepuasan Kerja terhadap Turnover Intention Karyawan. Diponegoro Journal of Manajement, 1, 1-13.

Melky, Y. (2015). Hubungan Kepuasan Kerja dan Komitmen Organisasi terhadap Intensi Pindah Kerja (Turnover Intention). Psikoborneo, 3(1), 98-111. http://ejournals.unmul.ac.id/index.php/psikoneo/article/view/3758

Monica, N. M. T. J., \& Putra, M. S. (2017). Pengaruh Stres Kerja, Komitmen Organisasional dan Kepuasan Kerja terhadap Turnover Intention. E-Jurnal Manajemen Unud, 6(3), 1644-1673.

Nafisah, C. A., Sunaryo, H., \& Wahono, B. (2020). Pengaruh Beban Kerja, Stres Kerja dan Lingkungan Kerja terhadap Turnover Intention pada Karyawan CV. Mitra Jaya Company Malang Oleh. Jurnal Ilmiah Riset Manajemen, 33-48. http://www.riset.unisma.ac.id/index.php/jrm/article/view/8199

Novitasari, D. (2020). Job Stress and Turnover Intention : Understanding the Role of Leadership and Organizational Commitment. International Journal of Science and Management Studies, 3(5), $1-14$.

O'Connor, J. (2018). The Impact of Job Satisfaction on the Turnover Intent of Executive Level Central Office Administrators in Texas Public School Districts: A Quantitative Study Of Work Related Constructs. Education Sciences, 8(2), 1-13. https://doi.org/10.3390/educsci8020069

Paat, G., Tewal, B., \& Jan, A. B. H. (2017). Pengaruh Komitmen Organisasi, Kepuasan Kerja, Stres Kerja terhadap Turnover Intention Karyawan Kantor Pusat PT. Bank Sulutgo Manado. Jurnal Emba: Jurnal Riset Ekonomi, Manajemen, Bisnis Dan Akuntansi, 5(3), 3444-3454. https://doi.org/10.35794/emba.v5i3.17568

Poeh, G. C., \& Soehari, T. D. (2017). Pengaruh Komitmen Organisasi, Kepuasan Kerja dan Stress Kerja terhadap Turnover Intention Guru Sekolah X Di Tangerang. Jurnal Swot, 7(2), 345-357.

Prabowo, R. (2018). Pengaruh Kepemimpinan dan Komitmen Organisasi terhadap Turnover Intention (Studi Pada Jajaran Reserse Kriminal Polres Gunungkidul). Jurnal Studi Keislaman, 4(2), 198219. https://doi.org/https://doi.org/10.5281/wahanaislamika.v4i2.29

Pranata, G. D., Salit, I. G., \& Netra, K. (2019). Pengaruh Stres Kerja terhadap Turnover Intention Melalui Mediasi Komitmen Organisasional pada Restoran Queen's Tandoor Seminyak. EJurnal Manajemen Universitas Udayana, 8(6), 3531-3559. https://doi.org/https://doi.org/10.24843/EJMUNUD.2019.v08.i06.p09

Prasetio, A. P., Martini, E., \& Mawaranti, R. P. (2018). Peran Stres Kerja dan Kepuasan Kerja Karyawan dalam Pengelolaan Tingkat Turnover Intention pada Karyawan Puskesmas Jasinga, Bogor. Jurnal Manajemen Indonesia, 18(2), 165-174. https://doi.org/10.25124/jmi.v18i2.1250

Ramalho Luz, C. M. D., Luiz de Paula, S., \& de Oliveira, L. M. B. (2018). Organizational Commitment, Job Satisfaction and Their Possible Influences on Intent To Turnover. Revista de Gestão, 25(1), 84-101. https://doi.org/10.1108/rege-12-2017-008

Ramlawati, R., Trisnawati, E., Yasin, N. A., \& Kurniawaty, K. (2021). External Alternatives, Job Stress on Job Satisfaction and Employee Turnover Intention. Management Science Letters, 11, 511-518. https://doi.org/10.5267/j.ms1.2020.9.016

Robbins, S. P., \& Judge, T. A. (2015). Organizational Behavior (16th ed.). New Jersey: Pearson. 
Dina Sabta Ratnaningsih, Pengaruh Kepuasan Kerja, Stres Kerja, dan Komitmen Organisasional terhadap Turnover Intention.

Santosa Halim, W. (2016). Analisis Rekrutmen dan Seleksi Karyawan pada Perusahaan Bihun Cahaya Tiga Tunggal. Agora, 4(1), 179-185.

Sentana, I. K. A. D., \& Surya, I. B. K. (2017). Pengaruh Kepuasan Kerja dan Komitmen Organisasional terhadap Turnover Intention. E-Jurnal Manajemen Unud, 6(10), 5232-5261.

Setiawan, A. (2017). Pengaruh Gaya Kepemimpinan Partisipatif terhadap Kinerja Karyawan melalui Motivasi Kerja dan Kepuasan Kerja. Agora, 5(3), 1-7.

Setiawan, D. P., \& Harahap, P. (2016). Pengaruh Komitmen Organisasi, Kompensasi, dan Karakteristik Pekerjaan terhadap Turnover Intention dengan Kepuasan Kerja sebagai Variabel Intervening (Studi Pada PT Sido Muncul Semarang). Jurnal Riset Ekonomi Dan Bisnis, 9(3), 56-79. https://doi.org/http://dx.doi.org/10.26623/jreb.v9i3.887

Singh, S. K., \& Singh, A. P. (2019). Interplay of Organizational Justice, Psychological Empowerment, Organizational Citizenship Behavior, and Job Satisfaction in the Context Of Circular Economy. Management Decision, 57, 937-952.

Soelton, M., \& Atnani, M. (2018). How Work Environment, Work Satisfaction, Work Stress on the Turnover Intention Affect University Management. Jurnal Manajemen Dan Bisnis Indonesia, 5(3), 439-448. https://doi.org/10.31843/jmbi.v5i3.178

Sopiah, \& Sangadji, E. M. (2020). The Effect of Job Stress on Turnover Intention Through Job Satisfaction of Government Commercial Bank Employees. International Conference on Islam, Economy, and Halal Industry, 2020, 66-82. https://doi.org/10.18502/kss.v4i9.7317

Sugiyono. (2016). Metode Penelitian Bisnis (16th ed.). Bandung: CV Alfabeta.

Suryanatha, A., \& Ardana, K. (2014). Pengaruh Kepemimpinan Transformasional dan Komitmen Organisasi terhadap Kepuasan Kerja Karyawan dan Organizational Citizenship Behavior (OCB) Pada Baleka Resort Hotel \& Spa Legian. E-Jurnal Manajemen Universitas Udayana, $3(4), 1155-1169$.

Sutardi, D., Novitasari, D., Asbari, M., Silitonga, N., Nugroho, Y. A., Hutagalung, D., Mustofa, Chidir, G., Basuki, S., \& Yuwono, T. (2020). Pengaruh Work-Family Conflict, Stres Kerja dan Social Support terhadap Kepuasan Kerja: Studi Kasus pada Guru Wanita di Tangerang. EduPsyCouns: Journal of Education, Psychology and Counseling, 2(1), 482-498. https://ummaspul.e-journal.id/Edupsycouns/article/view/513

Tampubolon, V. S., \& Sagala, E. J. (2020). Pengaruh Kepuasan Kerja dan Komitmen Organisasi terhadap Turnover Intention pada Karyawan Pt. Bum Divisi Pmks. Business Management Journal, 16(2), 65-80.

Wijono, S. (2015). Psikologi Industri \& Organisasi. Jakarta: Prenamedia Group.

Zhang, W., Meng, H., Yang, S., \& Liu, D. (2018). The Influence of Professional Identity, Job Satisfaction, and Work Engagement on Turnover Intention among Township Health Inspectors in China. International Journal of Environmental Research and Public Health, 15(5), 1-13. https://doi.org/10.3390/ijerph15050988 